\title{
Phylogenetic Relationships Among Basal-most Arthrodontous Mosses with Special Emphasis on the Evolutionary Significance of the Funariineae
}

\section{BERNARD GOFFINET}

Department of Botany, Box 90339, Duke University, Durham, NC 27708-0339, U.S.A. Current address: Department of Ecology and Evolutionary Biology U-43, University of Connecticut, Storrs, CT 06269-3043, U.S.A.

\section{Cymon J. CoX}

Department of Botany, The Natural History Museum, Cromwell Road, London, England, SW7 5BD, U.K. Current address: Department of Botany, Box 90339, Duke University, Durham, NC 27708-0339, U.S.A.

\begin{abstract}
The classification of the Bryopsida (mosses) has been based primarily on the variation of sporophytic characters i.e., architectural features of the peristome teeth that line the capsule mouth. Five arthrodontous peristome types have been recognized. Whether peristome types define natural groups and how they are evolutionary related has, however, remained unclear. Nucleotide sequence data from one nuclear and two chloroplast loci are generated and compiled to test two contrasting hypotheses regarding the ancestral peristome type in the Arthrodonteae. The genomic data partitions are incongruent with regard to the phylogenetic signal they carry. All phylogenetic analyses converge toward the polyphyly of the Funariineae and the Funariaceae. The Funariaceae are defined by the loss of a codon in the rps 4 gene. Goniomitrium acuminatum, the type of the genus, lacks this deletion, and is always resolved within the Haplolepideae. Consequently Goniomitrium is transferred to the Pottiaceae. The Ephemeraceae and Splachnobryaceae are tentatively retained as distinct, but with strong affinities to the Pottiineae. Neither the combined nor the independent data sets yield well supported topologies under the parsimony optimality criterion. Hence, the relationships among major lineages remain ambiguous. Inferences from chloroplast data alone yield a basal dichotomy between taxa with alternate peristomes (Orthotrichales and Bryales sensu lato) and those with opposite peristomes (Encalyptineae, Disceliaceae, Funariaceae, Timmiaceae, and the Haplolepideae). In contrast, analyses of the combined data resolve the Timmiaceae as sister to the split between the two peristomial lineages. It is hypothesized that the symmetric divisions of the IPL cells, is a synapomorphy for at least the Encalyptineae-Funariineae clade. The endostomial appendages of the timmiaceous peristome could, under either phylogenetic hypothesis, be regarded as homologous to the cilia in the bryoid peristome. Although the relationships among major lineages of arthrodontous mosses remain ambiguous, this study suggests that taxa with reduced or no peristomes, such as the Disceliaceae and the Gigaspermaceae, may be crucial in resolving the early evolutionary history of the Arthrodonteae when using DNA sequences.
\end{abstract}

Arthrodontous mosses are defined by the architecture of their peristome teeth. In contrast to nematodontous mosses (the Polytrichales and Tetraphidales) whose teeth are solid, and built from whole cells, the teeth that line the mouth of arthrodontous mosses, are composed of cell wall remnants, and in particular of periclinal cell plates. The architecture of the peristome teeth varies among major lineages of arthrodontous mosses. Vitt (1981) recognized four main peristome types that differ in their basic architecture at maturity. The haplolepideous peristome or Dicranum-type peristome is typically reduced to an endostome of 16 teeth, whose inner surface is built from one and a half columns of cells. The remaining three types are diplolepideous, that is they are typically composed of two rows of teeth, with the outer teeth bearing remnants of two columns of cells (hence the name diplolepideous). In the Funaria-type peristome, the exostome teeth lie opposite the endostome segments. By contrast, in the Orthotrichum- and Bryum-types, the outer teeth alternate with the inner segments. The latter type is further unique by the presence of endostomial cilia between the segments, a character correlated to the presence of additional cells in the inner most peristomial layer (IPL). These architectural differences observed at maturity are complemented by ontogenetic variations in the type of cell divisions in the IPL. In the Funaria-type peristome, the divisions that lead to a doubling of the number of IPL cells from eight to 16 are all symmetric, and the new anticlinal walls are perfectly aligned, with the anticlinal walls of the adjacent primary peristomial layer (PPL - Shaw 
et al. 1989a), whereas in the remaining three types, these divisions are asymmetric, and hence the new wall, is not aligned with the adjacent PPL wall (Goffinet et al. 1999; Shaw et al. 1989a,b). Vitt (1984) later also considered the peristome of the Encalyptineae to be distinct enough to warrant its recognition as a distinct architectural type. In the Encalyptineae the teeth and segments appear opposite as in Funaria and in the Haplolepideae (see Vitt et al. 1998), but the exostome can also bear intermediate teeth alternating with the endostomial segments (Edwards 1984; Horton 1982).

The polarity of peristome-type evolution has remained controversial, due to the uncertainty regarding the sister-group to the Arthrodonteae, to the lack of a robust phylogeny for mosses, and to the difficulty of assessing homology among peristomial features (Goffinet et al. 1999; Vitt et al. 1998). Vitt $(1981,1984)$ proposed that the Funaria-type peristome represents the most basic peristome architecture from which other types are derived. By contrast, Shaw and Rohrer (1984) considered the peristome of Funaria to be the product of reduction from a ciliate bryalean type peristome. The opposite arrangement of peristomes would consequently appear as a derived feature. Recent reconstructions of the phylogeny of mosses from mitochondrial (Beckert et al. 1999), chloroplast (Goffinet et al., unpubl.), and nuclear (Newton et al. 2000) sequence variations converge toward the Diphysciaceae (i.e., Diphyscium Mohr, Muscoflorschutzia Crosby, and Theriotia Card.) forming the sistergroup to the Arthrodonteae. Because the IPL division is asymmetric in Diphyscium, Goffinet et al. (1999) argued that this character should at present be considered plesiomorphic in the Arthrodontae, rather than derived from an ancestral symmetric division as suggested by Vitt $(1981,1984)$. This hypothesis does, however, not preclude an early origin of the Funariineae in the evolutionary history of the Arthrodonteae. Analyses of $r b c \mathrm{~L}$ sequences resolved the Funariaceae sister to a clade comprising the Orthotrichineae, Dicranineae, Bryineae, and Splachnineae (Goffinet et al. 1998), with the Encalyptineae sister to either this large clade or only to the Dicranineae. Cox and Hedderson (1999), analyzing a more extensive taxon sample using chloroplast and nuclear data, examined the relationships within the Arthrodonteae rooted to Funaria based on evidence from a broader analysis of $18 \mathrm{~S}$ rDNA sequences (Hedderson et al. 1996, 1998). Their analyses resolve the Orthotrichineae and the Splachnineae nested within the Bryineae, and the Encalyptineae and Haplolepideae composing a basal grade. Furthermore, they indicated that the Timmiaceae, that were resolved in a nested position within this basal grade, may be crucial for eluci- dating the relationships among major lineages of the Bryopsida (sensu Vitt 1984).

The Funariineae sensu Vitt (1984) comprise five families, namely the Funariaceae, Pseudoditrichaceae, Disceliaceae, Gigaspermaceae, and Ephemeraceae. Shaw (1984) excluded the monospecific Pseudoditrichaceae and transferred it near the Bryaceae (Bryineae) based on peristomial characters. The Gigaspermaceae and the Ephemeraceae are composed of gymnostomous taxa only. The peristome of the Disceliaceae is reduced; the endostome consists of a thin transparent membrane, adherent to the exostome, whereas the exostome is well developed and composed of sixteen teeth (Shaw \& Allen 1985). The longitudinal anticlinal walls of the IPL appear aligned with those of the adjacent PPL, a feature present only in the Funariineae and the Encalyptineae (Shaw \& Allen 1985). In the Funariaceae, the peristome is either well developed, reduced and simple, or lacking (Fife 1985). When well developed, the peristome of the Funariaceae is diplolepideous, with the endostome segments opposite or co-radially aligned to the exostome teeth. Cilia are always lacking and the peristome formula is typically $4: 2: 4$, with the IPL lacking additional cellular divisions, which are characteristic of typical Bryales with cilia. The cells of the IPL are all similar, if not identical, in size as a consequence of the symmetric divisions (Shaw et al. 1989a). In the absence of sporophytic features for most taxa, the Funariineae have traditionally been defined by the similarities in vegetative characters, such as smooth cells, costate leaves, undifferentiated alar cells, and large calyptrae (Vitt 1982). Except for the Gigaspermaceae that are cladocarpous (LaFarge-England 1996), the Funariineae sensu Vitt are typical acrocarpous taxa (Fife 1980). Koponen (1981) erected the Splachnobryaceae, a small family restricted to the genus Splachnobryum C. Müll., and transferred it from the Pottiineae to the Funariineae, based on the diplolepideous rather than haplolepideous architecture of the peristome. Koponen (1981) further argued for Splachnobryum having a rather basal position among arthrodontous moss phylogeny, on the basis of the lateral solitary gametangia. The peristome is, however, reduced to a single row of 16 rather short teeth, whose architecture Allen and Pursell (2000) interpret as of the haplolepideous type. The circumscription of the Funariidae (sensu Vitt 1984), and the relationships among the families currently accepted within the order, have not been critically examined using a phylogenetic approach.

Assuming that Diphyscium and its close relatives compose the closest outgroup to the Arthrodonteae, this study will address the circumscription of the Funariineae, the relationships among its families, and examine the significance of the Funaria-type 
peristome in the evolution of peristome types in the Arthrodonteae. Specifically, the following questions will be addressed 1) are the Funariineae sensu Vitt (1984) monophyletic? 2) what is the significance of the Funariineae in the early diversification of the Arthrodonteae? and 3) what are the trends in the evolution of peristomial characters in the Arthrodonteae?

\section{Material AND Methods}

Taxon sampling.-Exemplars of arthrodontous taxa potentially representing early cladogenic events, with a main emphasis on the Funariineae, sensu Vitt (1984) were sampled (Table 1). Duplicate taxonomic sampling was performed for selected taxa as primarily analyses progressed, to confirm sequences; duplicate taxa were retained even when the additional sequences diverged by a single nucleotide. The matrix was completed by retrieving sequences from GenBank, primarily for diplolepideous mosses (Cox \& Hedderson 1999). Vouchers are deposited in DUKE unless otherwise indicated in Table 1.

DNA extraction, PCR amplification, and sequencing.Apical portions of stems or branches, or in the case of ephemeral taxa, operculate capsule(s), were removed from dried herbarium collections. DNA was extracted from plant tissues following the protocol outlined in Goffinet et al. (1998). Plant material was ground using a small glass test tube, in $250 \mu \mathrm{L}$ of $2 \mathrm{X}$ CTAB (hexadecyltrimethylamonium bromide)- $0.2 \%$ beta-mercaptoethanol, heated to $60^{\circ} \mathrm{C}$, and incubated at this temperature for at least $30 \mathrm{~min}$. An equal volume of chloroform-isoamyl (24:1) was added. The emulsified solution was centrifuged for one min. at 6,500 rpm, and the aqueous phase was transferred to a new tube to which an equal volume of ice cold isopropanol was added. DNA was precipitated at $4^{\circ} \mathrm{C}$ for 30-60 min. Tubes were centrifuged first for $10 \mathrm{~min}$. at $13,000 \mathrm{rpm}$. The pellet was washed with $70 \%$ ethanol, and the tubes centrifuged for three min at $13,000 \mathrm{rpm}$. The pellet was dried in a vacuum centrifuge and suspended in $100 \mu \mathrm{L}$ TE (Tris-EDTA, pH 8.0). Protocols (of) for the amplification(s) of the $t r n \mathrm{~L}-t r n \mathrm{~F}$ and $r p s 4$ regions as well as the sequencing of the fragments followed those presented in Buck et al. (2000). Amplification and sequencing of the 18S rRNA gene followed the protocol described in Cox et al. (2000). Labeled fragments yielded by the sequencing reactions were separated on polyacrylamide gels (Long Range Singel; FMC Bioproducts), using an ABI Prism 373 or 377 automated DNA sequencer (Perkin Elmer). Nucleotide sequences were edited using Sequencher 3.0 (Gene Codes Corporation), entered in Paup version 4.0b2a (Swofford 1999) and manually aligned. The intron, exon, and spacer composing the $\operatorname{trn} \mathrm{L}-\operatorname{trn} \mathrm{F}$ product were delimited by comparing the sequences with available GenBank accessions. Aligned trnL-trnF sequences were trimmed of the 5'exon of the $\operatorname{trn} \mathrm{L}$, and the $\operatorname{trn} \mathrm{F}$ exon (leaving the $\operatorname{trn} \mathrm{L}$ intron, $\operatorname{trn} \mathrm{L}-3^{\prime}$ exon, and the trnL-trnF spacer), while the first 27 sites (including the annealing site of the primer) and the intergenic spacer following the stop codon were excluded from the rps 4 sequences. Sequences of the $18 \mathrm{~S}$ rRNA gene were trimmed at both ends at sites corresponding to the amplification primer annealing sites. All sequences obtained in this study were submitted to GenBank (Table 1).

Phylogenetic analysis.-All analyses and tests were performed using PAUP version 4.0b2a (Swofford 1999) on a Macintosh G3 $400 \mathrm{MHz}$. Maximum parsimony (MP,
Fitch 1971) was chosen as the optimality criterion for the phylogenetic analyses. Parsimony analyses were performed with equal weighting of characters and transformations. For each analysis searches were replicated 100 times, with random sequence addition. The steepest descent option was selected. A partition homogeneity test was performed using the same set of options to examine whether phylogenetic signal carried by the nuclear and chloroplast sequences are congruent or whether they recover distinct histories. Consistency indices (CI) and rescaled consistency indices (RC) were calculated with PAUP. Fifty thousand random trees were generated and the $g_{1}$ (Huelsenbeck 1991) statistic describing the tree length frequency distribution was compute with Paup. Relative strength of support for particular branches was estimated using bootstrap analysis (Felsenstein 1985; Hillis \& Bull 1993) based on 100 bootstrap replicates of the heuristic search with the same set of options in effect as above (except for 10 search replicates). Support for the branches was evaluated by Bremer support analysis, using the program Autodecay (Eriksson 1998).

Finally, constraint trees were employed to assess the effect of alternative phylogenetic hypotheses on the tree length. Tree scores of the constrained trees were compared to that of unconstrained trees by non-parametric (Templeton 1983) and parametric (Kishino \& Hasegawa 1989) testing.

\section{RESUlts}

Sequence variation.-Sequences for the $18 \mathrm{~S}$ rRNA and $r p s 4$ genes and for the $\operatorname{trn} \mathrm{L}-\operatorname{trn} \mathrm{F}$ region were assembled for 39 taxa. 18S rDNA sequences were not obtained for Discelium nudum (Disceliaceae) and the taxon is therefore not included in the combined analysis. Eighty-two sequences were generated in the course of this study (Table 1). Alignment of sequences resulted in a matrix of 3,430 characters of which 807 were excluded, either because these sites corresponded to the amplification primer sequences, or the homology assumptions required for these sites were considered ambiguous (the matrix is available from the senior author). The 2,623 characters included in the analyses consisted of 1,740 nt from the $18 \mathrm{~S}$ rRNA gene, $570 \mathrm{nt}$ of the rps 4 gene and $313 \mathrm{nt}$ of the $\operatorname{trn} \mathrm{L}-\operatorname{trnF}$ region. Approximately $13 \%$ (i.e., 331) of the sites used, were parsimony informative, with the $18 \mathrm{~S}$ rDNA accounting for $34 \%$ (i.e., 111 sites) of these sites, whereas the rps 4 gene and the $\operatorname{trn} \mathrm{L}-\operatorname{trn} \mathrm{F}$ region carried 149 (i.e., $45 \%$ of all informative sites) and 71 (i.e., 21\%) informative sites, respectively. Although indels per se were not examined for their phylogenetic signal, all members of the Funariaceae except Goniomitrium acuminatum shared the absence of a codon in the rps 4 gene. The distribution of the tree length of 50,000 randomly generated trees from the data used here, was significantly leftskewed $(p<0.01)$, suggesting that the data set appears more structured than what would be expected from a random set of data, and thus that the data may carry the signal necessary for resolving the 
phylogenetic history of the taxa (Hillis \& Huelsenbeck 1992). The partition homogeneity test indicates that the chloroplast and nuclear data partitions are incongruent $(p<0.01)$. That is, the chloroplast and nuclear sequences appear to possess conflicting historical signals based on the assumptions implicit in the use of the parsimony criterion and the options invoked during the tree search procedure.

Phylogenetic analyses.-All analyses consistently resolve the Funariaceae and Funariineae as polyphyletic lineages. Goniomitrium acuminatum, which lacks the codon loss in the rps 4 shared by all other Funariaceae, appears nested within the Haplolepideae. The Ephemeraceae and Splachnobryaceae are also resolved within the Haplolepideae. The phylogenetic position of the Splachnobryaceae is determined primarily by chloroplast data, as analyses of $18 \mathrm{~S}$ rDNA sequence data result in it being nested within the Funariaceae. However, Splachnobryum does possess the codon that is absent from the other members of the Funariaceae. Enforcing the monophyly of either the Funariaceae or the Funariineae sensu Vitt (1984) using the 18S sequences results in topologies whose length is significantly worse $(p<0.001)$.

Phylogenetic inferences from a combined data set resulted in two most parsimonious hypotheses (tree length $=1,363$, CI with autapomorphic characters excluded $=0.441, \mathrm{RC}=0.384$; Fig. 1 ). In both trees the Timmiaceae are resolved as the sister-group to the remaining ingroup taxa. The Archidiaceae are consistently nested within the Haplolepideae. The Orthotrichales, Splachnales (including Meesiaceae), and Bartramiales form a monophyletic group characterized by a bootstrap percentage (BP) of 86 and a decay index (DI) of three. In the sister clade to this diplolepideous alternate clade, the Haplolepideae share a common ancestor with a lineage comprising the Gigaspermaceae, Encalyptineae, and the Funariineae. Within the latter clade the Funariaceae appear more closely related to the Encalyptaceae than to the Gigaspermaceae. None of the branches defining the relationships among these major lineages is defined by BP higher than 50, and the DI vary between one and two. Considering the possible heterogeneity of the signal carried by both partitions (nuclear and chloroplast data), separate analyses were performed. When using the $18 \mathrm{~S}$ rDNA sequences alone, at least 5,000 equally most parsimonious trees (tree length $=414$, CI without autapomorphies $=0.496$, and $\mathrm{RC}=0.502$ ) were obtained (result not shown). The Funariaceae (excl. Goniomitrium acuminatum) were resolved sister to clade composed of all other Arthrodonteae, wherein the Timmiaceae were resolved as the basal-most lineage (see also Cox et al. 2000; Newton et al. 2000). Within the large clade, neither the Encalyptaceae, the Gigaspermaceae, nor the Haplolepideae was defined as a monophyletic taxon, and the Orthotrichaceae were nested within the Haplolepideae. Similarly, the genera Aphanorrhegma (Funariaceae) and Lorentziella (Gigaspermaceae) were resolved as para- or polyphyletic.

The analysis of the chloroplast data yielded two most parsimonious trees (Fig. 2), of length 889, characterized by a consistency index (CI) of 0.56 ( 0.46 when autapomorphic characters are removed) and a rescaled consistency index (RC) of 0.39. Here the Haplolepideae, Funariaceae (excl. Goniomitrium acuminatum), and the Gigaspermaceae are monophyletic. Furthermore, these taxa compose a natural group that is sister to the Timmiaceae. This inclusive clade shares a common ancestor with the remaining diplolepideous mosses. This topology is retained upon the exclusion of the third codon position of the rps 4 gene, or the inclusion of Discelium in the analysis. In the resulting single MPT in the latter analysis (tree length $=909, \mathrm{CI}=0.56$, $\mathrm{RC}=0.38)$ Discelium is nested between the Gigaspermaceae and the Funariaceae-Encalyptaceae clade (Fig. 2). Most basal internodes remain defined by low BT and DI values.

\section{DISCUSSION}

The Funariineae are primarily defined by vegetative characters, because many taxa (genera or even families) are gymnostomous or characterized by otherwise reduced peristomes. Such a systematic concept of the Funariineae does not withstand phylogenetic testing. Neither nuclear nor chloroplast data, whether analyzed in combination or separately, support a monophyletic Funariineae as traditionally defined (e.g., Vitt 1984). Moreover, the monophyly of these taxa is even strongly rejected by the data presented here. The Ephemeraceae, a small, but widespread family of minute ephemeral mosses, are consistently resolved within the Haplolepideae. The lack of a peristome and the lack of strong gametophytic differentiation of the Ephemeraceae preclude reciprocal testing of this hypothesis using morphological data at present. A placement within the Pottiineae, and maybe even within the Pottiaceae, is certainly a viable hypothesis, considering that the Pottiaceae include many taxa having undergone severe morphological reduction (see Zander 1993). The affinities of the Ephemeraceae within the Haplolepideae are currently being further examined and preliminary results, based on rps 4 data for species of Micromitrium corroborate a relationship of the Ephemeraceae with the Pottiaceae (Goffinet et al., unpubl.). Goniomitrium acuminatum, traditionally included in the Funariaceae (Fife 


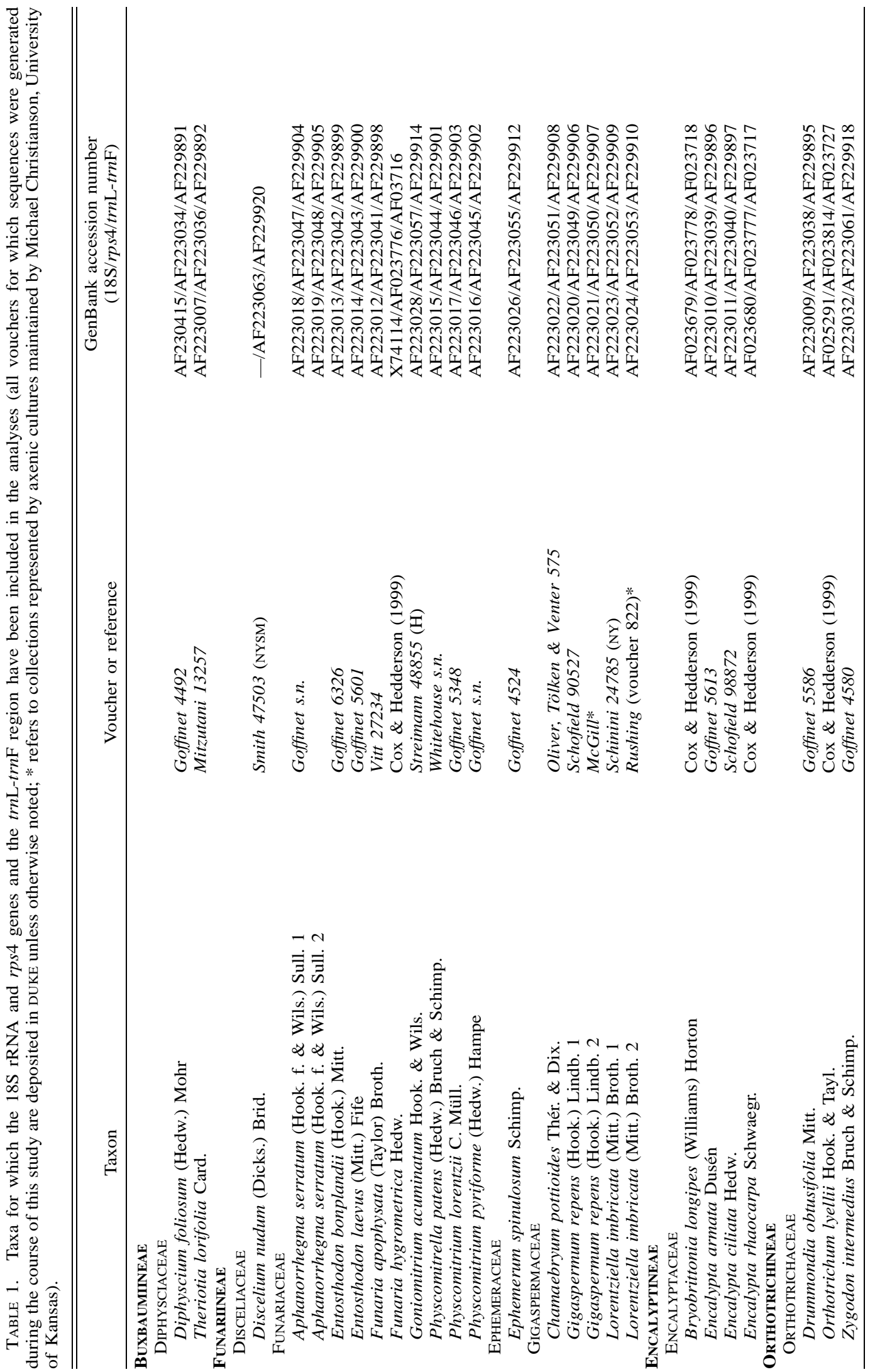




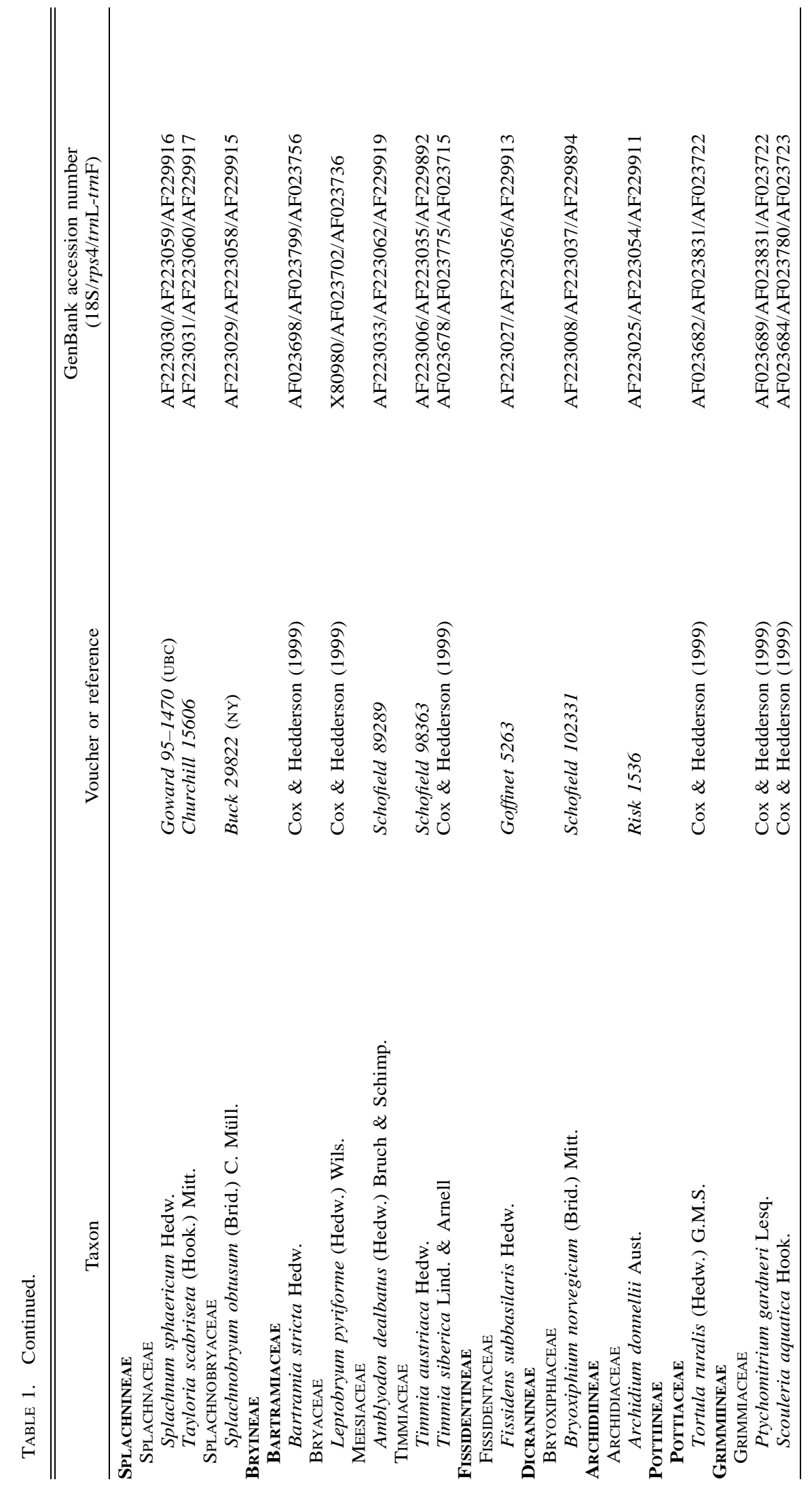




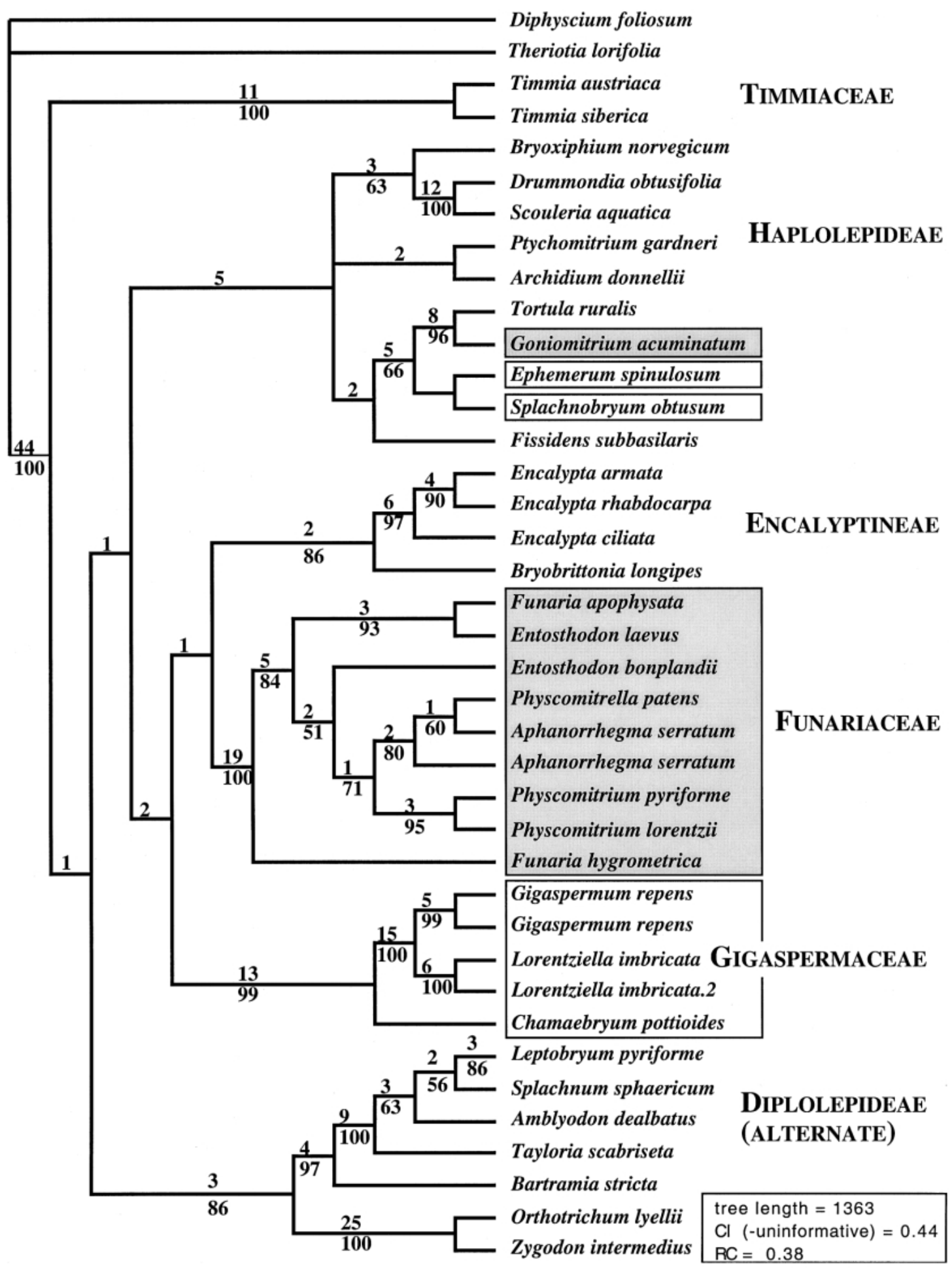

FIGURE 1. Strict consensus of two equally most parsimonious trees obtained from analyzing the nuclear and chloroplast data combined. Bootstrap percentages $(>50 \%)$ are presented below the branches and decay indices above. Boxed taxa belonged to the Funariineae sensu Vitt, and the shaded boxes further more composed the Funariaceae sensu Vitt (1984). 


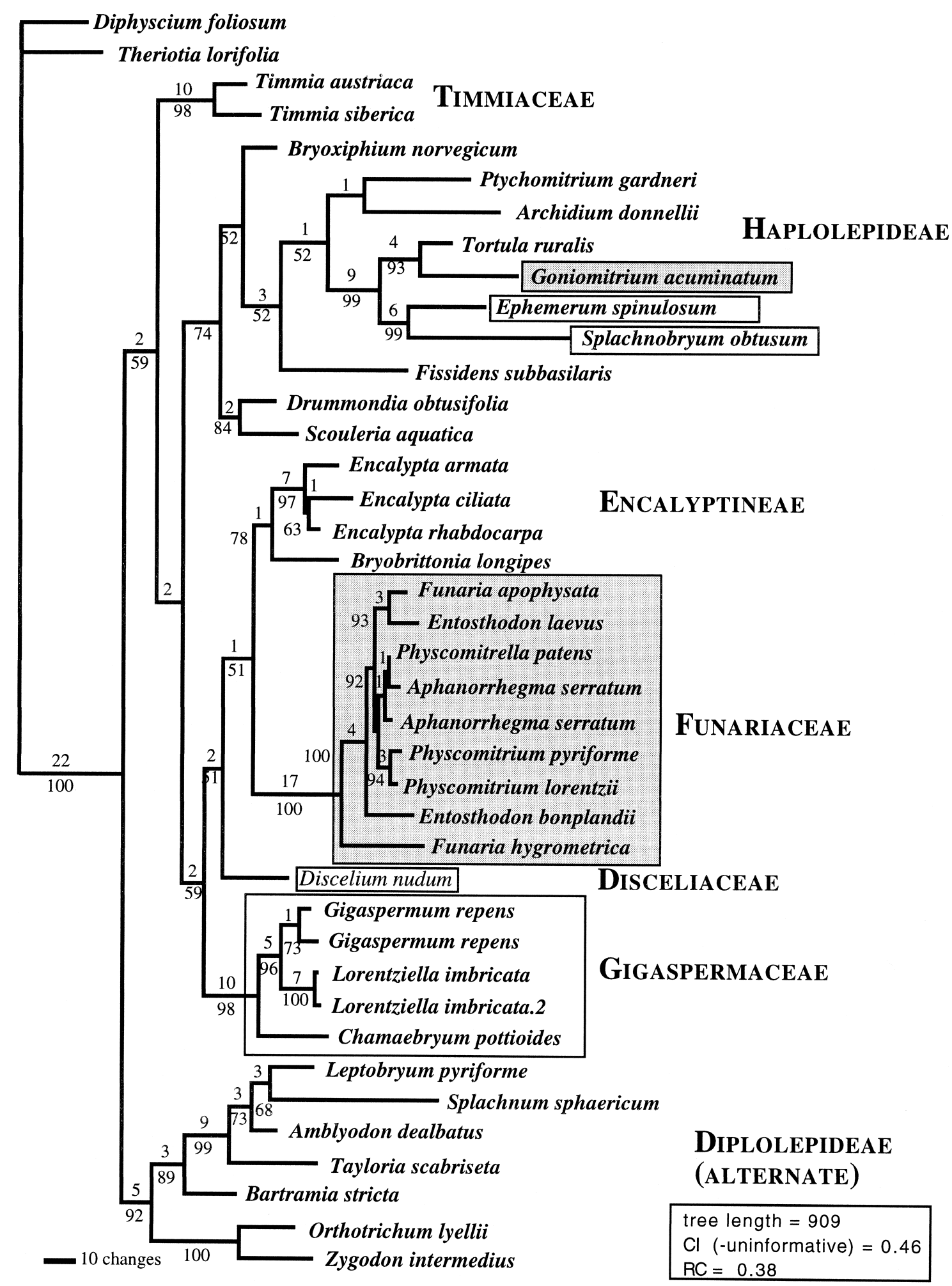

FIGURE 2. Phylogram of single most parsimonious trees obtained from analyzing chloroplast data ( $r p s 4$ and $t r n \mathrm{~L}-$ $\operatorname{trnF}$ region) independently for a taxon sample that includes Discelium. Bootstrap percentages $(>50 \%)$ are presented below the branches and decay indices above. Boxed taxa belonged to the Funariineae sensu Vitt, and the shaded boxes further more composed the Funariaceae sensu Vitt (1984). 
1985) and considered with strong affinities to $\mathrm{Fu}$ naria (Stone 1981), is also shown to be more closely related to the Haplolepideae and to Tortula (Pottiaceae) in particular (BT $=96$ and DI $=8$ ). The genus Goniomitrium comprises five species, and is defined by an overall reduce morphology (Fife 1985). The phylogenetic affinities of Goniomitrium within the Pottiaceae is beyond the scope of this study and will be examined critically elsewhere.

The phylogenetic relationships of Splachnobryum, a pantropical genus also composed of minute mosses, have remained controversial. Robinson (1971) and Crum and Anderson (1981) among others, placed the genus within the Pottiaceae, whereas Vitt $(1982,1984)$ retained the genus within the Splachnaceae as proposed earlier by Brotherus (1924). Koponen (1981) accommodated the genus in its own family, and argued against affinities with the Pottiaceae, on the basis of diplolepideous features of the peristome. Affinities to the Splachnaceae were rejected due to the lack of differentiated hypophysis. Instead, Koponen proposed to transfer the Splachnobryaceae to the Funariineae. As mentioned above, the Funariineae have been defined mainly by vegetative characters. Many of these characters are, however, considered plesiomorphic in mosses (Crosby 1980; Vitt 1982), and could be reacquired following reduction (e.g., loss of papillae results in smooth cells). The most parsimonious inferences from nuclear sequences are congruent with Koponen's hypothesis, even though the genus is resolved in a nested position within the Funariaceae. Such paraphyly of the Funariaceae seems, however, incompatible with Splachnobryum lacking the loss of a codon within its rps 4 sequence, a character otherwise shared by all other Funariaceae sampled (except Goniomitrium acuminatum, see above). In contrast, phylogenetic inferences from chloroplast data suggest that Splachnobryum is allied to the Haplolepideae. Allen and Pursell (2000) recently re-examined the peristome of Splachnobryum and argued for a haplolepideous rather than diplolepideous architecture, an interpretation congruent with the chloroplast-based phylogenetic hypothesis presented here.

Phylogenetic inferences regarding the early diversification of Arthrodontous mosses based on nuclear (18S rDNA) and chloroplast (rps4 and $\operatorname{trn\mathrm {L}-}$ $\operatorname{trn} \mathrm{F})$ sequences separately yielded incongruent results. However, neither the nuclear nor the chloroplast data yielded topologies with internal branches well supported by bootstrap values or decay indices. The nuclear data resolved many well established taxa as polyphyletic (e.g., the Haplolepideae were polyphyletic and included the Orthotrichaceae; the Encalyptaceae were paraphyletic; and so were Aphanorrhegma and Lorentziella based on two conspecific samples) whereas the chloroplast data consistently resolved at least the peristomate taxa in major groups in accordance with traditional peristome-based systematic concepts (e.g., Funariineae, Dicranineae). We will therefore discuss primarily the topologies inferred from chloroplast data.

In the analyses of the combined data or the chloroplast data alone the Encalyptaceae form a sister group to the Funariaceae. The peristome of Funaria hygrometrica is composed of two rows, with the endostome segments positioned opposite the exostome teeth. The segments are raised on a high basal membrane formed from an IPL that is composed of 32 identical cells as a result of perfectly symmetric divisions (Shaw et al. 1989a). The peristome of the Encalyptaceae varies in architecture (Edwards 1984; Horton 1982, 1983), with regard to the number and structure of the teeth. Edwards (1984) found no evidence of sesquilepideae (i.e., a 2:3 cell pattern between the PPL and IPL characteristic of the Dicranum-type peristome). The endostome segments never bear a vertical line on their outer surface, and are always facing the exostome teeth, as in the Funaria-type peristome. Some of the species have narrow intermediate teeth that alternate with the segments. This situation is not homologous to that found in the Bryum-type peristome, since, in the latter, the segments bear remnants of the longitudinal anticlinal wall of the PPL on the outer surface (Edwards 1984). This arrangement is therefore only analogous to that of the Bryales sensu lato. Developmental studies further indicate that the divisions in the IPL are also aligned with the plane of the adjacent PPL wall, although the timing may be different from that observed in Funaria (Shaw, pers. comm.). The sister relationship between the Encalyptineae and the Funariineae, as suggested by chloroplast data, is consequently not incongruent with the sporophytic features. This phylogenetic hypothesis is, although the most parsimonious, poorly supported and in conflict with analyses based on broader character sampling (see Cox et al. 2000; Newton et al. 2000). The ancestor to this group may be mostclosely related to the Disceliaceae (Fig. 2). The peristome of Discelium, albeit reduced (Shaw \& Allen 1985), is consistent with defining this broad clade by an opposite peristome. Furthermore, anatomical studies of immature capsules reveal that the anticlinal walls of the IPL are all perfectly aligned with those of the PPL, suggesting that the divisions are symmetric (Shaw \& Allen 1985).

The Gigaspermaceae are resolved as the sistergroup to this broad diplolepideous-opposite clade. Its members are, however, consistently gymnostomous, and therefore offer no information for recon- 
structing ancestral peristome types. The development of the sporophyte in the Gigaspermaceae has been studied by Rushing and Snider (1980). The ontogenetic patterns of cell divisions within the amphithecium of Lorentziella imbricata, a species included here, does not follow that of the fundamental square as in other mosses, and the divisions within the layers are not synchronized. Rushing and Snider (1980) do not specifically address each set of divisions, but from their figure 7 , within which three of the eight IPL have undergone an anticlinal division, it appears that the new walls are laid down in the same plane as the adjacent PPL walls. The divisions can thus be characterized as symmetric. This mode of IPL cell division may serve as a synapomorphy for the clade comprising the Gigaspermaceae, Encalyptineae, and Funariineae.

Inferences from chloroplast data suggest that the sister-group to this Funarialean-Encalyptalean clade is the Haplolepideae; a hypothesis retained upon analysis of the combined data set, but in conflict with the analyses by Cox et al. (2000) and Newton et al. (2000). The peristome of the Haplolepideae is typically single, and composed of the endostome only. When the exostome is present, the teeth are always poorly developed and adherent to the endostomial segments, and clearly positioned opposite to the latter. That this observation is not an artifact can be established by the position of the teeth with regard to the anticlinal walls of the PPL. The teeth are indeed always formed between two consecutive anticlinal walls of the PPL (Shaw et al. $1989 b$ ), as in the Funaria-type peristome and can thus only lie opposite the exostomial teeth (Vitt et al. 1998). The clade composed of the Funariineae, Encalyptineae, and the Haplolepideae can therefore be characterized by its opposite peristomes. Unlike in the Funariineae, the development of the haplolepideous peristome proceeds through a stage characterized by an asymmetric division. Whether the asymmetric division in the ILP should be considered plesiotypic compared to the symmetric one of the Funariineae and Encalyptineae is not clear.

The Timmiaceae and a clade composed of the Orthotrichineae and Bryineae sensu lato form a grade at the base of the Arthrodonteae (Figs. 1-2). The development of the timmiaceous peristome has not been studied, except for the latest stages (Murphy 1988). Prior to the deposition of the wall material, anticlinal walls of IPL adjacent to those of the PPL, appear in some cases well aligned, whereas in others, they are not (Murphy 1988). The pattern deviates from the perfect alignment of all walls in well-developed peristomes of the Funariineae (Schwartz 1994, see also Goffinet et al. 1999), but is similar to that observed in the Splachnineae and the Orthotrichineae. Partial asymmetry may repre- sent an ancestral type of division from which more severe asymmetries have evolved (i.e., those typical of the Haplolepideae and the Bryales sensu lato; Shaw et al. 1989a,b). Weak asymmetries occur also in Tetraphis (Goffinet et al. 1999; Shaw \& Anderson 1988), whereas in Diphyscium, they are more pronounced (Shaw et al. 1987). If indeed the divisions in Timmia are asymmetric, then the symmetric division represents a synapomorphy for the Encalyptineae and Funariineae.

The peristome of the Timmiaceae is unique among diplolepideous mosses in the architecture of the endostome. This inner row is composed of a high basal membrane supporting 64 filamentous appendages, arranged into groups of four that are opposite the exostome teeth at maturity. As in other opposite peristomes, these appendages lack any anticlinal wall remnants of the PPL on their outer surface (Murphy 1988; Shaw \& Rohrer 1984). Whether the opposite arrangement of the peristomes is an apomorphy or a plesiomorphy for the clade comprising the Funariineae, Encalyptineae, Haplolepideae, and Timmiaceae (as presented in Fig. 1) remains unclear since the endostome of Diphyscium (the Theriotia peristome was not examined) consists of a pleated membrane that lacks individual segments. The exostome of Diphyscium is composed of 16 teeth separated by 16 intermediate teeth. The latter are characterized by a median vertical wall on their inner surface, and are fused to the outer pleats of the endostome (Edwards 1984). The true teeth thus alternate with the pleats. A basal membrane of the endostome is particularly pleated in taxa with alternate peristomes (see Shaw et al. 1989a), but also albeit less so, in lineages with opposite peristomes (Edwards 1984; Schwartz 1994). The pleats themselves are thus not an indication of the arrangement of the peristomes. Consequently, the lack of differentiated segments in Diphyscium precludes from determining its "putative" arrangement. Inclusion of the nuclear data in the analysis (or analyzing the nuclear data alone) resolves Timmia sister to a dichotomy between lineages with either opposite or alternate peristome, suggesting that the latter peristome configuration is derived.

The typical Bryum-type peristome bears cilia between the segments. The occurrence of cilia is seemingly correlated to additional divisions in the IPL, leading to at least 48 cells composing the IPL. In the Orthotrichaceae, cilia are always lacking and the IPL is composed of 32 cells at most. The relationships of the Orthotrichaceae remain ambiguous (Cox \& Hedderson 1999; Cox et al. 2000; Goffinet et al. 1998), but a sister-group relationship to the Bryales sensu lato as resolved here, rather than a nested position within the latter, cannot be ruled out. Depending on the homology assumption made 
for the appendages of the Timmiaceae, cilia could, based on the chloroplast based phylogeny have arisen in the ancestor to either the Arthrodonteae (excluding the "Diphysciaceae") or to the Bryales only. The appendages present in the endostome of the Timmiaceae are monomorphic, whereas in the Bryales sensu lato, these are dimorphic; cilia and segments have distinct architectures (Shaw \& Rohrer 1984). The appendages present in the Timmiaceae are similar to cilia in that they lack remnants of the anticlinal PPL walls on the outer surface, and in their position opposite the teeth. The endostome of the Timmiaceae is also characterized by additional divisions leading to more than 32 cells in the IPL (Murphy 1988; Shaw \& Rohrer 1984), as is also typical of ciliate bryoid peristomes. It is thus possible that at least some appendages of the timmiaceous endostome are homologous to the cilia of the typical Bryum-type peristome, as suggested by Shaw and Rohrer (1984). Support for this hypothesis will depend on the phylogenetic affinities of the diplolepideous alternate mosses lacking cilia (e.g., Orthotrichales, and Splachnales; see Goffinet et al. 1999) and the interpretation of their peristome (see Cox et al. 2000).

The phylogenetic relationships among basalmost arthrodontous mosses hypothesized here based on chloroplast data are congruent with inferences made from mitochondrial sequences (Beckert et al. 1999), but are incongruent with those derived from analyses of the nuclear 18S rRNA gene (this study, and see also Cox et al. 2000; Hedderson et al. 1996, 1998; Newton et al. 2000). Whether this conflict results from ancestral hybridization or reflects the inadequacy of either set of characters for deep-level reconstructions needs to be addressed further. However, both the nuclear and the chloroplast do concur with regard to the polyphyly of the Funariineae and the Funariaceae. These results highlight again the usefulness of the molecular characters in addressing the circumscription of taxa characterized by morphological reduction (i.e., loss or reversal of characters). Our analyses reveal further that taxa lacking critical morphological features should not be omitted from phylogenetic analyses because of their limited contribution in resolving trends of morphological evolution, as these taxa, such as the Disceliaceae or the Gigaspermaceae, may be highly relevant for resolving the relationships among lineages of arthrodontous mosses.

\section{ACKNOWLEDGEMENTS}

This study was made possible through the financial support provided by Duke-University, NSF-grant DEB9806955, and the Natural History Museum (London) Research Fund. Michael Christiansen (U. of Kansas) kindly shared some of his inherited axenic cultures. Assistance by William Buck (NY) and Norton Miller (N.Y. State Museum) in locating material of Lorentziella imbricata and Discelium nudum is very much appreciated. Sandra Boles (DUKE) provided valuable assistance for which we are grateful. Support from the Green Plant Phylogeny Research Coordination Group through USDA grant 9437105-0713 from DOE/NSF/USDA for attendance of the XVI International Botanical Congress and various workshops is gratefully acknowledged. Finally, we would like to thank the curators of the herbaria $(\mathrm{H}, \mathrm{NY}, \mathrm{UBC})$ for their permission to sample the collection for DNA extractions.

\section{Literature Cited}

Allen, B. \& R. A. Pursell. 2000. A reconsideration of the systematic position of Splachnobryum. Journal of the Hattori Botanical Laboratory 88: (in press).

Beckert, S., S. Steinhauser, H. Muhle \& V. Knoop. 1999. A molecular phylogeny of bryophytes based on nucleotide sequences of the mitochondrial nad5 gene. Plant Systematics and Evolution 218: 179-192.

Brotherus, V. F. 1924. Splachnaceae, pp. 333-334. In A. Engler (ed.), Die natürlichen Pflanzenfamilien 10, ed. 2. Leipzig.

Buck, W. R., B. Goffinet \& A. J. Shaw. 2000. Testing morphological concepts of orders of pleurocarpous mosses (Bryophyta) using phylogenetic reconstructions based on trn L-trnF and rps4 sequences. Molecular Phylogenetics and Evolution 10: (in press).

Cox, C. J. \& T. A. Hedderson. 1999. Phylogenetic relationships among the ciliate arthrodontous mosses: evidence from chloroplast and nuclear DNA sequences. Plant Systematics and Evolution 215: 119-139.

- , B. Goffinet, A. E. Newton, J. Shaw \& T. A. J. HedDERSON. 2000. Phylogenetic relationships among the diplolepideous-alternate mosses (Bryidae) inferred from nuclear and chloroplast DNA sequences. THE BRYOLOGIST 103: 224-241.

Crosby M. R. 1980. The diversity and relationships of mosses, pp. 115-129. In R. J. Taylor \& A. E. Leviton (eds.), The Mosses of North America. California Academy of Science, San Francisco.

Crum, H. A. \& L. E. Anderson. 1981. Mosses of Eastern North America. 1. Columbia University Press, NY.

EDWARDS, S. R. 1984. Homologies and inter-relations of moss peristomes, pp. 658-695. In R. M. Schuster (ed.), New Manual of Bryology, Vol. 2. Hattori Botanical Laboratory, Nichinan, Japan.

ERIKSSON, T. 1998. AutoDecay ver. 4.0 (program distributed by the author). Department of Botany, Stockholm University. Stockholm.

Felsenstein, J. 1985. Confidence limits on phylogenies: An approach using the bootstrap. Evolution 39: 783791.

FIFE, A. J. 1980. The affinities of Costesia and Neosharpiella and notes on the Gigaspermaceae. THE BRYOLOGIST 83: 466-476.

1985. A generic revision of the Funariaceae (Bryophyta: Musci). Part I. Journal of the Hattori Botanical Laboratory 58: 149-196.

FITCH, W. M. 1971. Toward defining the course of evolution: Minimum change for a specific tree topology. Systematic Zoology 20: 406-416.

Goffinet, B., R. J. BAyeR \& D. H. VitT. 1998. Circumscription and phylogeny of the Orthotrichales (Bryopsida) inferred from $r b c \mathrm{~L}$ sequence analysis. American Journal of Botany 85: 1324-1337.

, A. J. Shaw, L. E. Anderson \& B. D. Mishler. 
1999. Peristome development in mosses in relation to systematics and evolution. V. Diplolepideae: Orthotrichaceae. THE BRYOLOGIST 102: 581-594.

Hedderson, T. A., R. L. Chapman \& W. L. Rootes. 1996. Phylogenetic relationships of bryophytes inferred from nuclear-encoded rRNA gene sequences. Plant Systematics and Evolution 200: 213-224.

- R. Chapman \& C. J. Cox. 1998. Bryophytes and the origins and diverification of land plants: new evidence from molecules, pp. 65-77. In J. W. Bates, N. W. Ashton \& J. G. Duckett (eds.), Bryology for the Twenty-First Century. Maney Publishing and British Bryological Society, Leeds, U. K.

Hillis, D. M. \& J. P. Huelsenbeck. 1992. Signal, noise, and reliability in molecular phylogenetic analyses. Journal of Heredity 83: 189-195.

\& J. J. Bull. 1993. An empirical test for bootstrapping as a method for assessing confidence in phylogenetic analysis. Systematic Biology 42: 182-192.

Horton, D. G. 1982. A revision of the Encalyptaceae (Musci) with particular reference to the North American taxa. Part I. Journal of the Hattori Botanical Laboratory 53: 365-418.

- 1983. A revision of the Encalyptaceae (Musci) with particular reference to the North American taxa. Part II. Journal of the Hattori Botanical Laboratory 54: 353-532.

Huelsenbeck, J. P. 1991. Tree length distribution skewness: an indicator of phylogenetic information. Systematic Zoology 41: 17-48.

Kishino, H. \& Hasegawa, M. 1989. Evaluation off the maximum likelihood estimate of the evolutionary tree topologies from DNA sequence data, and the branching order in Homonoidea. Journal of Molecular Evolution 29: 170-179.

Koponen, A. 1981. Splachnobryaceae, a new moss family. Annales Botanici Fennici 18: 123-132.

LA FARGe-England, C. 1996. Growth form, branching pattern, and perichaetial position in mosses: Cladocarpy and pleurocarpy revisited. The Bryologist 99: 170186.

Murphy, S. A. 1988. Development of the Peristome of Timmia megapolitana Hedw. M.Sc. thesis, University of Iowa, Iowa City, Iowa.

Newton, A. E., C. Cox, J. G. Duckett, J. Wheeler, B. Goffinet, T. A. J. Hedderson \& B. D. Mishler. 2000. Evolution of the major moss lineages: phylogenetic analyses based on multiple gene sequences and morphology. THE BRYOLOGIST 103: 187-211.

Robinson, H. 1971. A revised classification for the orders and families of mosses. Phytologia 21: 289-293.

Rushing, A. E. \& J. A. SNIDER. 1980. Observations of sporophyte development in Lorentziella imbricata (Mitt.) Broth. Journal of the Hattori Botanical Laboratory 47: 35-44.

SchwartZ, O. M. 1994. The development of the peri- stome-forming layers in the Funariaceae. International Journal of Plant Sciences 155: 640-657.

SHAW, J. 1984. A reinterpretation of peristome structure in Pseudoditrichum mirabile Steere \& Iwats. (Pseudoditrichaceae). THE BRYOLOGIST 87: 314-318.

\& B. H. Allen. 1985. Anatomy and morphology of the peristome in Discelium nudum (Musci: Disceliaceae). THE BRYOLOGIST 88: 263-267.

\& L. E. ANDERSON. 1988. Peristome development in mosses in relation to systematics and evolution. II. Tetraphis pellucida (Tetraphidaceae). American Journal of Botany 75: 1019-1032.

— \& B. D. Mishler. 1987. Peristome development in mosses in relation to systematics and evolution. I. Diphyscium foliosum (Buxbaumiaceae). Memoirs of the New York Botanical Garden 45: 5570 .

1989a. Peristome develop ment in mosses in relation to systematics and evolution. III. Funaria hygrometrica, Bryum pseudocapillare, and B. bicolor. Systematic Botany 14: 24-36.

, B. D. Mishler \& L. E. Anderson. 1989b. Peristome development in mosses in relation to systematics and evolution. IV. Haplolepideae: Ditrichaceae and Dicranaceae. THE BRYOLOGIST 92: 314-325.

\& J. R. Rohrer. 1984. Endostomial architecture in diplolepideous mosses. Journal of the Hattori Botanical Laboratory 57: 41-61.

Stone, I. G. 1981. Spore morphology and some features of Goniomitrium Hook. \& Wils. (Funariaceae). Journal of Bryology 11: 491-500.

Swofford, D. L. 1999. PAUP.* Phylogenetic Analysis using Parsimony (*and other methods). Version 4. Sinauer Associates, Sunderland, MA.

Templeton, A. R. 1983. Phylogenetic inference from restriction endonuclease cleavage site maps with particular reference to the humans and apes. Evolution 37: 221-244.

VITT, D. H. 1981. Adaptive modes of the moss sporophyte. The Bryologist 84: 166-186.

. 1982. Sphagnopsida and Bryopsida, pp. 305, 307-336. In S. P. Parker (ed.), Synopsis and Classification of living organisms, Vol. 1. McGraw-Hill, NY. . 1984. Classification of the Bryopsida, pp. 696759. In R. M. Schuster (ed.), New Manual of Bryology, Vol. 2. Hattori Botanical Laboratory, Nichinen, Japan.

- , B. Goffinet \& T. A. Hedderson. 1998. The ordinal classification of the mosses: Questions and answers for the 1990's, pp. 143-159. In J. W. Bates, N. W. Ashton \& J. G. Duckett (eds.), Bryology for the Twenty-first Century.Maney Publishing and British Bryological Society, Leeds, U.K.

ZANDER, R. H. 1993. Genera of the Pottiaceae: mosses of harsh environments. Bulletin of the Buffalo Society of Natural Sciences 32: 1-378.

ms. received Nov. 15, 1999; accepted Feb. 8, 2000. 